\title{
Overexpression of glycine-extended gastrin in transgenic mice results in increased colonic proliferation
}

\author{
Theodore J. Koh, ${ }^{1}$ Graham J. Dockray, ${ }^{2}$ Andrea Varro, ${ }^{2}$ Rachel J. Cahill, ${ }^{3}$ \\ Charles A. Dangler, ${ }^{3}$ James G. Fox, ${ }^{3}$ and Timothy C. Wang ${ }^{1}$
}

${ }^{1}$ Gastrointestinal Unit, Department of Medicine, Massachusetts General Hospital, Boston, Massachusetts 02114, USA
${ }^{2}$ Physiological Laboratory, University of Liverpool, L69 3BX Liverpool, United Kingdom
${ }^{3}$ Division of Comparative Medicine, Massachusetts Institute of Technology, Cambridge, Massachusetts 02139, USA

Address correspondence to: Timothy C. Wang, Gastrointestinal Unit, Department of Medicine, Massachusetts General Hospital, Boston, Massachusetts 02114, USA. Phone: (617) 726-9228; Fax: (617) 726-3673; E-mail: wang@helix.mgh.harvard.edu

Received for publication August 13, 1998, and accepted in revised form March 11, 1999.

\begin{abstract}
Gastrin is a peptide hormone involved in the growth of both normal and malignant gastrointestinal tissue. Recent studies suggest that the glycine-extended biosynthetic intermediates mediate many of these trophic effects, but the in vivo relevance of glycine-extended gastrin (G-Gly) has not been tested. We have generated mice (MTI/G-GLY) that overexpress progastrin truncated at glycine-72 to evaluate the trophic effects of G-Gly in an in vivo model. MTI/G-GLY mice have elevated serum and colonic mucosal levels of G-Gly compared with wild-type mice. MTI/G-GLY mice had a $43 \%$ increase in colonic mucosal thickness and a $41 \%$ increase in the percentage of goblet cells per crypt. MTI/G-GLY mice exhibited increased colonic proliferation compared with wild-type controls, with an expansion of the proliferative zone into the upper third of the colonic crypts. Continuous infusion of G-Gly into gastrin-deficient mice for two weeks also resulted in elevated G-Gly levels, a $10 \%$ increase in colonic mucosal thickness, and an $81 \%$ increase in colonic proliferation when compared with gastrin-deficient mice that received saline alone. To our knowledge, these studies demonstrate for the first time that G-Gly's contribute to colonic mucosal proliferation in vivo.
\end{abstract}

J. Clin. Invest. 103:1119-1126 (1999).

\section{Introduction}

Gastrin is a peptide hormone that is important in the regulation of acid secretion and growth of both normal and malignant gastrointestinal tissue (1). The role of amidated gastrin (e.g., G-17) as a trophic factor for the oxyntic mucosa of the stomach was shown in studies by Johnson and others in the early 1970s (2-4). Recent studies in transgenic mice have confirmed that the overexpression of amidated gastrin results in increased proliferation and hypertrophy of the gastric mucosa (5). Mice made gastrin-deficient by targeted gene disruption exhibit gastric mucosal atrophy and a loss of parietal cells, although basal proliferation rates are unchanged, suggesting that gastrin may affect cell lineage decisions by the gastric stem cell (6).

The role of the incompletely processed forms of gastrin is less clear. Gastrin is initially synthesized as the prohormone preprogastrin, which is then cleaved by a signal peptidase to form progastrin. Progastrin is then processed in the secretory vesicles of neuroendocrine cells through cleavage by trypsin-like endopeptidases and carboxypeptidase $\mathrm{E}$ to form the glycine-extended processing intermediate G-34-GLY. G-34-GLY is then processed to form either G-17-GLY or G-34, with G-34 being further processed to form $\mathrm{G}-17(7,8)$. It was widely believed that the nonamidated gastrins, which account for $5 \%$ of all secreted gastrin peptides in humans (9), had no biologic activity until G-34-GLY underwent alpha amidation to form amidated gastrin, as this is the only form of gastrin that can bind to the CCK-B/gastrin receptor. However, recent studies suggest that the lessprocessed forms of gastrin have growth factor properties in their own right. Progastrin and glycine-extended gastrin (G-Gly) are the predominant forms of gastrin found in many tumors, including colon (10-12), lung (13), ovarian (14), and neuroendocrine (9). G-17-GLY $(15,16)$ and progastrin (17) have been shown to stimulate the growth of several cancer cell lines as well as nontransformed colon cells (18). Traditional CCK-B/gastrin antagonists cannot block this growth response, and GGly appears to use a different signaling pathway compared with amidated gastrin (19), suggesting the existence of a novel gastrin receptor. Three candidate receptors for these incompletely processed forms of gastrin have been identified (15-17), but at present, the precise identity of the receptor for the incompletely processed gastrins remains unclear.

That the less-processed forms of gastrin may have growth factor properties suggests a possible role in the growth and development of the normal colon. The gastrin gene is expressed in the rat fetal colon with a rapid decline at birth, followed by a gradual reappearance of gastrin mRNA levels by 21 days (20). The adult rat colon expresses both progastrin and G-Gly (20). Elevated circulating levels of human progastrin in transgenic mice result in increased colonic proliferation as measured by 5-bromo-2'-deoxyuridine (BrdU) uptake (5). Conversely, gastrin-deficient mice generated in our laboratory have been shown to have a lower rate of colonic proliferation (6). Because the normal colon does not express the CCK- 
$\mathrm{B} /$ gastrin receptor (21), these findings support the notion that the decreased rate of proliferation seen in gastrin-deficient mice is due to the absence of the incompletely processed forms of gastrin.

Recent studies have raised the possibility that G-Gly plays an important role in regulating the growth of the colonic mucosa. Stable transfection of a nontransformed colon cell line (YAMC) with a gastrin construct resulted in increased intracellular and extracellular levels of G-Gly and an increased proliferation rate (18). To our knowledge, there have been no in vivo studies performed to assess the role of G-Gly in regulating the growth of the colon.

The trophic effects of the less-processed forms of gastrin may also be important in the biology of colon cancer. It has been shown that the vast majority of human colon cancers express the less-processed forms of gastrin $(12,22)$. In vitro studies have shown that the growth of colon cancer cell lines can be inhibited by transfection with gastrin antisense cDNA constructs (23). The nonspecific gastrin inhibitors proglumide and benzotript, which appear to bind the $78-\mathrm{kDa}$ potential receptor for the incompletely processed forms of gastrin (24), can inhibit the growth of colon cancer cell lines (25) as well as transplanted colon carcinomas (26). Patients with Zollinger-Ellison syndrome, which results in elevated levels of circulating amidated gastrin, G-Gly, and progastrin, also have increased colonic proliferation rates and a shift in the proliferative zone into the upper third of the crypt $(27,28)$. Increased colonic proliferation and the expansion of the proliferative zone into the upper third of the crypt have been associated with an increased risk of developing colon cancer in humans $(29,30)$.

We have generated mice (MTI/G-GLY) that overexpress a form of G-Gly, resulting in elevated levels of G-Gly in both the serum and in the colon. To our knowledge, these transgenic mice provide the first in vivo model for testing the growth factor properties of G-Gly, the form of gastrin most used in experiments showing the trophic effects of incompletely processed forms of gastrin.

\section{Methods}

Plasmid construction. The human gastrin cDNA was altered by PCR mutagenesis by placing two stop codons after glycine-72 (Gly-72) using the PCR primers 5'-TAGATCTCAGACGAGATGCAGCG ACTATGT and 5'-TAGATCTATTAGCCGAAGTCCATCCATCCATCCATA. These PCR primers also contain BglII restriction sites for cloning into the metallothionein promoter construct. The resulting mutated gastrin gene was then cloned into the BglII site of EV 142 (kind gift of R.D. Palmiter, University of Washington, Seattle, Washington, USA) (31), downstream of the mouse metallothionein promoter and upstream of the human growth hormone poly(A) tail (Figure 1).

Injection fragments and microinjection techniques. DNA fragments were prepared for microinjection by restriction digest with EcoRI, gel electroelution, cesium chloride density gradient centrifugation, and dialysis with injection buffer, as previously described (32). Microinjections into the male pronucleus of fertilized eggs from FVB inbred (Taconic Farms Inc., Germantown, New York, USA) matings were performed as previously described (32). The resulting pups were tested at three weeks of age for the presence of the transgene by Southern blot analysis using a human gastrin exon 2 probe generated by the Megaprime DNA Labeling System (Amersham Life Sciences Inc., Arlington Heights, Illinois, USA).

Northern blot analysis. RNA was prepared from homogenized tissue extracts from seven- to eight-week-old mice using the Trizol method (GIBCO BRL, Gaithersburg, Maryland, USA). RNA blots were performed by standard techniques using $10 \mathrm{mg}$ of RNA per well. Blots were hybridized with a $\left[\alpha-{ }^{32} \mathrm{P}\right] \mathrm{dCTP}-$ labeled human gastrin exon 2 random-primed probe or a GAPDH randomprimed probe made with the Megaprime labeling kit.

RT-PCR analysis. RT-PCR was performed using the GeneAmp RNA PCR kit (Perkin-Elmer Corp., Norwalk, Connecticut, USA) on a GeneAmp PCR System 9700 (Perkin-Elmer Corp.). RNA was obtained as a template by the Trizol method as already described, and then RT-PCR was performed using the primer pair 5'CTGAAGCTTCTTGGAAGCCC and 5'-CAGGGGACAGGGCTGAAGTG (GAS). The antisense primer is complementary to the $3^{\prime}$ gastrin sequences that are absent from the transgene, so a PCR product will not be generated if only the transgene cDNA is present. To detect RNA transcripts from the MTI/G-GLY transgene, another primer pair, 5' - CTGAAGCTTCTTGGAAGCCC and 5'CTGCTTCTTGGACGGGTCT (GLY), was used. Here, the downstream primer is proximal to the MTI/G-GLY stop codon and will generate an RT-PCR product (173 bp) when either the full-length gastrin transcript or the MTI/G-GLY transcript is used as a template. The reverse transcription was performed as one cycle of $42^{\circ} \mathrm{C}$ for $15 \mathrm{~min}, 99^{\circ} \mathrm{C}$ for five minutes, and $5^{\circ} \mathrm{C}$ for five minutes. The resulting cDNA was amplified with an initial denaturation at $95^{\circ} \mathrm{C}$ for $105 \mathrm{~s}$, followed by 35 cycles of $95^{\circ} \mathrm{C}$ for $15 \mathrm{~s}, 60^{\circ} \mathrm{C}$ for $30 \mathrm{~s}$, and a final extension step at $72^{\circ} \mathrm{C}$ for seven minutes.

BrdU immunohistochemistry. Six 7- to 8-week-old MTI/G-GLY mice (three each from two different lines) and six FVB control mice were injected with $\mathrm{BrdU}(50 \mathrm{mg} / \mathrm{kg}$ intraperitoneally) and were killed one hour later. Tissue samples were placed in a cassette, immersed in Carnoy's fixative overnight, and embedded in paraffin wax. Immunohistochemical detection of the BrdU
Figure 1

Map of the MTI/G-GLY transgene. The MTI/G-GLY transgene was generated by PCR mutagenesis of the human gastrin cDNA by placing a stop codon after Gly-72. It was then inserted into the Bg/ll site of EV142, a plasmid containing the mouse metallothionein promoter and the human growth hormone poly(A) tail (31). Mice expressing the MTI/G-GLY transgene have elevated levels of G-Gly in the serum and in many organs, including the colon and the lung.
277

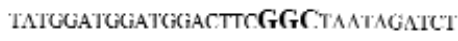

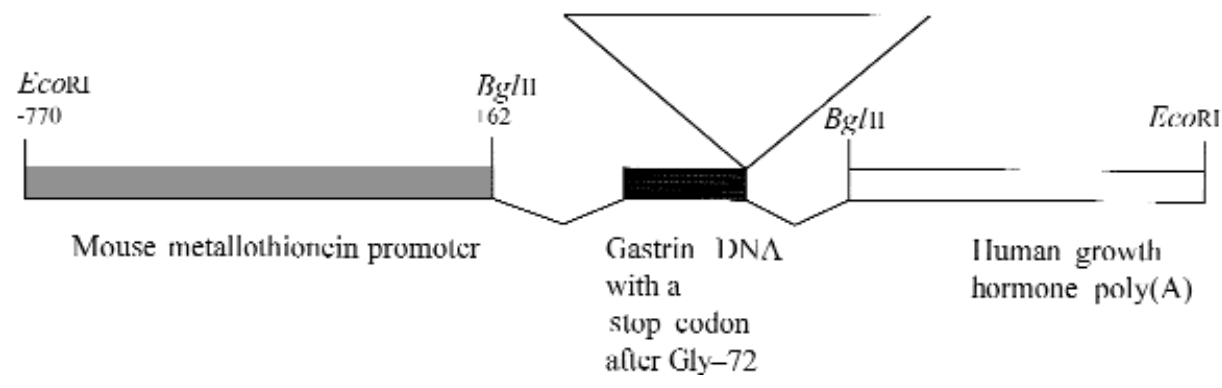


incorporation was performed using the avidin-biotin monoclonal antibody technique as described previously (5).

Ten well-oriented oxyntic glands or colonic crypts were counted per slide. Of the 10 colonic crypts, four were obtained from the rectum, three from the descending colon, and three from the ascending colon. The BrdU labeling index was calculated by counting the number of BrdU-positive cells per gland/crypt and expressing the result as a percentage of the total number of cells per gland/crypt.

Calculation of glandular/colonic height. Slides were stained with hematoxylin and eosin (H\&E). Ten gastric glands or colonic crypts whose lumens could be seen throughout their entire length were counted per section and measured with an FW10X micrometer eyepiece (Olympus Optical Co., Tokyo, Japan) along its perpendicular axis, as described previously (6).

Extraction and assay for gastrin peptides. Tissue samples (100 mg) were boiled in $1 \mathrm{ml}$ water for $15 \mathrm{~min}$, homogenized, and centrifuged $(5,000 \mathrm{~g}, 15 \mathrm{~min})$. The supernatant was recovered and frozen. Serum was obtained by tail bleeding for assay of circulating gastrin (8). Gastrin concentrations were determined by radioimmunoassay using antibodies to the $\mathrm{COOH}$-terminus of G-Gly and amidated gastrin (antibodies 109-21 and L2, respectively) (8). Further characterization of the G-Gly was performed by immunoprecipitation (8) of serum using antibodies specific for the $\mathrm{NH}_{2}$-terminus of human G-17 (1295), G-34 (L66), and progastrin (L482), and radioimmunoassay of the supernatant using antibodies to $\mathrm{COOH}$-terminal G-Gly $(109-21)(33,34)$. The antibody to the $\mathrm{NH}_{2}$-terminus of human progastrin was raised in a rabbit immunized with the peptide SWKPRSQQPYC coupled to maleimide-activated keyhole limpet hemocyanin as described previously (8).

Infusion of gastrin into gastrin-deficient mice. Gastrin-deficient mice were generated by targeted homologous recombination as described previously (6). Eighteen 3-month-old gastrin-deficient mice were implanted with 2-week Alzet osmotic pumps (Alza Corp., Palo Alto, California, USA) containing either saline, G-17 $(10 \mathrm{nmol} / \mathrm{kg} / \mathrm{h})$, or G-17-GLY $(10 \mathrm{nmol} / \mathrm{kg} / \mathrm{h})$. Serum samples were obtained by tail bleeding at seven days. Thirteen days after pump implantation, the mice were fasted, with free access to water. The next day, they were injected with BrdU $(50 \mathrm{mg} / \mathrm{kg})$ and sacrificed one hour later. The tissue samples were fixed in Carnoy's solution and embedded in paraffin; routine H\&E and BrdU staining were performed as already described.

Data analysis. Statistical analysis was determined by the twotailed Student's $t$ test, with $P<0.05$ used as a measure of statistical significance. All results are expressed as mean \pm SD.

\section{Results}

MTI/G-GLY transgenic mice express glycine-extended progastrin. To demonstrate that the MTI/G-GLY construct would express the expected mRNA product, transient transfection studies with the MTI/G-GLY construct were performed in the HuH7 cell line. Northern blot analysis confirmed that HuH7-transfected cells were able to transcribe the MTI/G-GLY gene product (Figure 2a).

Five founder lines were generated that incorporated the MTI/G-GLY transgene into the germ line as detected by Southern blot analysis using a probe to human gastrin exon 2. The MTI/G-GLY transgene was expressed in the mouse kidney, liver, colon, stomach, liver, and pancreas, as detected by Northern blot analysis using the same probe to human gastrin exon 2 (Figure 2a). Expression of the MTI/G-GLY gene was further confirmed by radioimmunoassay of peptide extracts using an antibody to the COOH-terminus of G-Gly. MTI/G-GLY mice had serum G-Gly concentrations of $85.0 \pm 28.0 \mathrm{pM}$ and serum amidated gastrin concentrations of $47.5 \pm 22.6$ pM. Immunodepletion of serum using antibodies specific for the $\mathrm{NH}_{2}$-terminus of human G-17, G-34, or progastrin revealed that the major circulating form of G-Gly is G-34-GLY. In wild-type mice, G-Gly's were undetectable in plasma $(<30 \mathrm{pM})$, and amidated gastrin concentrations were comparable to those found in MTI/GGLY mice $(55.8 \pm 6.5 \mathrm{pM})$. The data therefore suggest that the MTI/G-GLY mice have elevated serum G-Gly levels (G-34-GLY) and normal amidated gastrin levels and do not support the idea that G-Gly might be converted to amidated gastrin in the MTI/G-GLY mice.

G-Gly concentrations in the colon of MTI/G-GLY mice were $11.7 \pm 1.23 \mathrm{pmol} / \mathrm{g}$ compared with $<2 \mathrm{pmol} / \mathrm{g}$ in wild-type mice. Amidated gastrin was not detectable in the colons of either the MTI/G-GLY or wild-type mice. Assays using antibodies specific for the $\mathrm{NH}_{2}$-terminus of human G17 and G34 revealed concentrations of immunoreactive material in the colon of MTI/G-GLY mice that were $10 \%$ or less those of G-Gly and were close to the limit of detection $(1 \mathrm{pmol} / \mathrm{g})$. The data suggest that approximately $90 \%$ of tissue G-Gly was not cleaved at Arg 57/58 or Lys 74/75, which is compatible with the

\section{c $\begin{array}{ccc}\text { Colon } & \text { Stomach } & \text { Control } \\ \text { GLY GAS } & \text { GLY GAS } & \text { GLY GAS }\end{array}$}

a

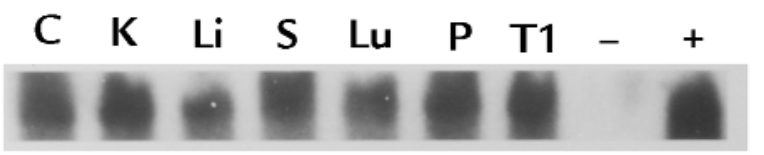

b
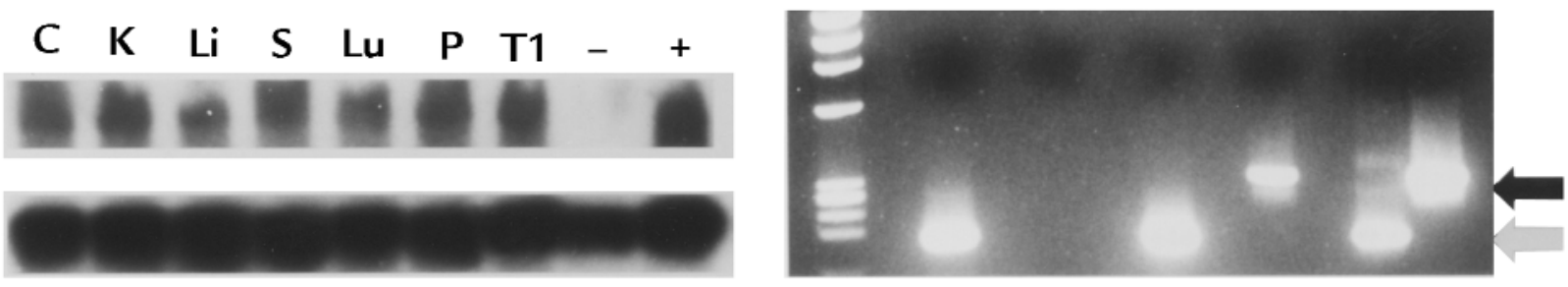

Figure 2

$\mathrm{MTI} / \mathrm{G}-\mathrm{GLY}$ transgenic mice express human G-Gly. (a) Northern blot analysis using a human gastrin cDNA probe reveals that human gastrin is being transcribed in the MTI/G-GLY mouse colon (C), kidney (K), liver ( $\mathrm{Li})$, stomach (S), lung (Lu), and pancreas (P). MTI/G-GLY is also transcribed in a transfected cell line (T1). RNA from hGAS kidney $(-)$ is used as a negative control, and liver RNA from hGAS transgenic mice $(+)$ is used as a positive control. (b) GAPDH controls from same blot. (c) RT-PCR reaction was performed using antisense primers (GLY) that are proximal to Gly-72, resulting in a 173-bp PCR product (open arrow), or primers (GAS) that are distal to Gly-72, resulting in a 322-bp PCR product (filled arrow). The colons of MTI/G-GLY mice produce the MTI/G-GLY transgene transcript but not the full-length gastrin transcript. The stomachs of MTI/G-GLY mice produce both transcripts. Liver RNA from hGAS mice (which overexpress human progastrin in the liver) was used as a control. 

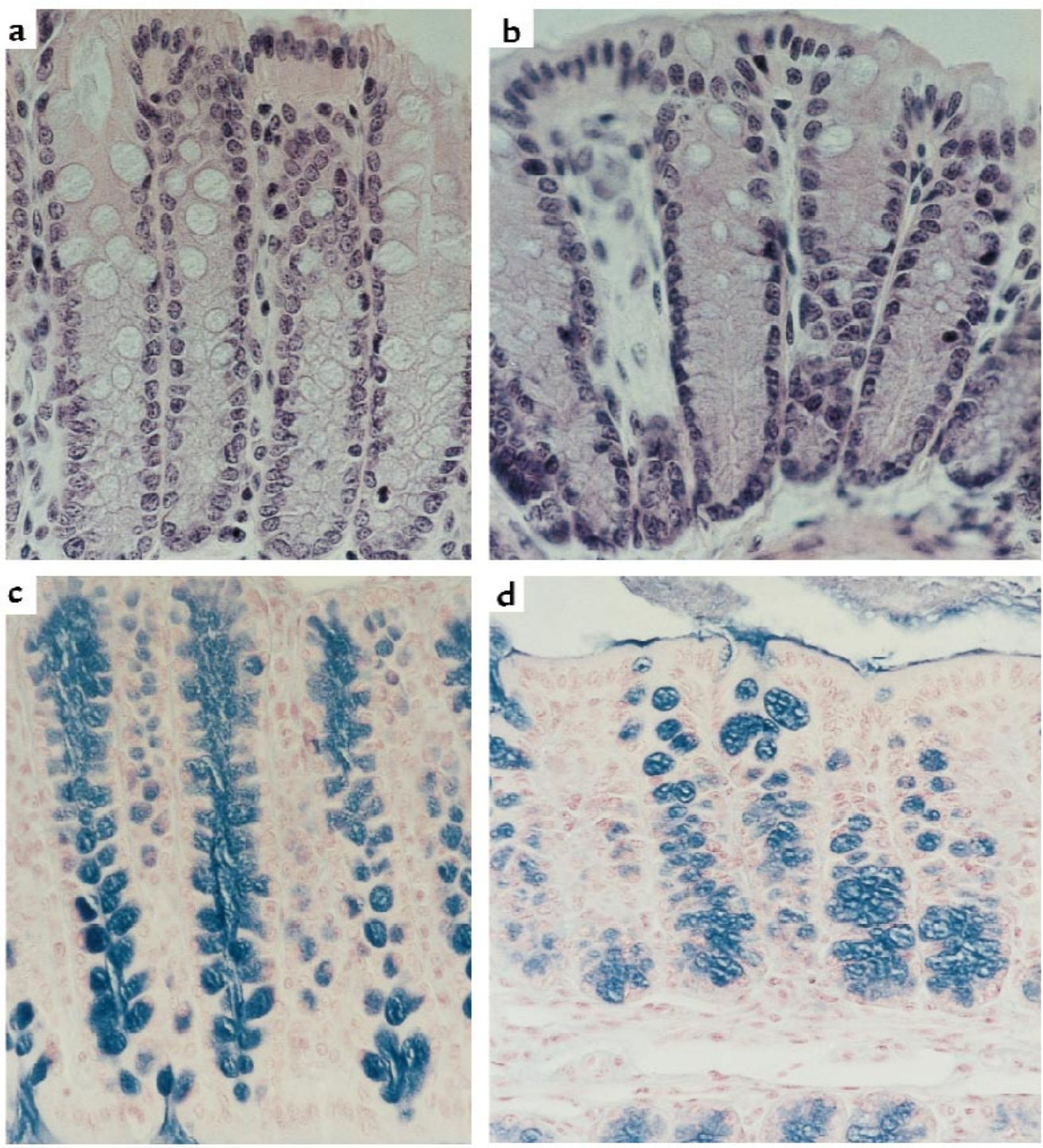

Figure 3

MTI/G-GLY mice have increased numbers of goblet cells in the colon. Three-month-old mice were sacrificed. On routine histology, the MTI/G-GLY mice (a) appear to have an increased number of goblet cells compared with wild-type mice (b). This result was confirmed by Alcian blue staining, which revealed an increased number of goblet cells in the MTI/G-GLY mice (c) compared with wild-type control (d).

idea that cleavage of the peptide to yield circulating G34-GLY occurs just before secretion.

To show further that the MTI/G-GLY gene product terminated after the Gly-72 residue, RT-PCR analysis was performed using RNA obtained from tissue extracts from either MTI/G-GLY mice or wild-type mice. Figure $2 \mathrm{~b}$ shows that in the colons of MTI/G-GLY mice, only truncated gastrin transcripts are present, consistent with the transcription of the MTI/G-GLY transgene. In the stomach of MTI/G-GLY mice, both the truncated and full-length gastrin transcripts are present, with the latter likely representing endogenous gastrin production.

MTI/G-GLY have goblet cell hyperplasia compared with wildtype mice. Routine histologic examination of the colon of three-month-old MTI/G-GLY mice from two different lines revealed a statistically significant increase in mucosal thickness $(0.995 \pm 0.033 \mathrm{~mm})$ when compared with wild-type FVB mice of the same age $(0.694 \pm 0.054$ $\mathrm{mm} ; P<0.05)$. There also appeared to be an increase in mucin-containing goblet cells in the colon (Figure 3, a and $b$ ). To evaluate this further, slides were stained with Alcian blue (Figure 3, c and d). The MTI/G-GLY mice had a significantly higher percentage of goblet cells per crypt $(20.4 \pm 3.3$ vs. $14.5 \pm 0.8 ; P<0.01)$ than did their wild-type controls.

Histologic analysis of the stomachs of MTI/G-GLY mice revealed no obvious differences when compared with wild-type mice. There was no difference in the thickness of the fundic mucosa in the MTI/G-GLY mice compared with wild-type. There were also no apparent differences seen in the kidney, liver, lung, and pancreas of MTI/G-GLY mice compared with wild-type mice at three months of age.

MTI/G-GLY-expressing mice have increased proliferation in the colon. Given the increased number of goblet cells seen and prior evidence that less-processed forms of gastrin 
can have trophic effects on the colon (5), we measured colonic proliferation using BrdU incorporation. Six MTI/G-GLY mice (three each from two separate lines) and six wild-type control mice were allowed to feed ad libitum and then were sacrificed at seven to eight weeks of age. They were given an intraperitoneal injection of BrdU one hour before sacrifice. The colon of the MTI/GGLY transgenic mice had a statistically higher proliferative index $(9.03 \pm 1.13)$ than did wild-type controls (4.14 $\pm 1.01 ; P<0.01$ ) (Table 1 ). In conjunction with these findings, the proliferative zone of the MTI/G-GLY mice extended beyond the base of the colonic crypts into the upper third of the colonic crypt when compared with wild-type mice (Figure 4, a and b).
In contrast, there was no difference seen in the labeling index of the stomachs of MTI/G-GLY transgenic mice (3.17 \pm 0.29$)$ compared with wild-type mice $(3.27 \pm 0.61)$. There was also no apparent change in the size or location of the proliferative zone in the gastric glands (Figure 4, c and d). This is similar to the findings seen in transgenic mice that have elevated serum progastrin levels.

MTI/G-GLY mice do not develop tumors of the gastrointestinal tract at one year. Given the increased colonic proliferation, $10 \mathrm{MTI} / \mathrm{G}-\mathrm{GLY}$ mice and five wild-type mice were sacrificed at one year of age and examined for possible tumor development. The colons of the MTI/G-GLY mice continued to show goblet cell hyperplasia, but no tumors were detectable by gross inspection or by histo-
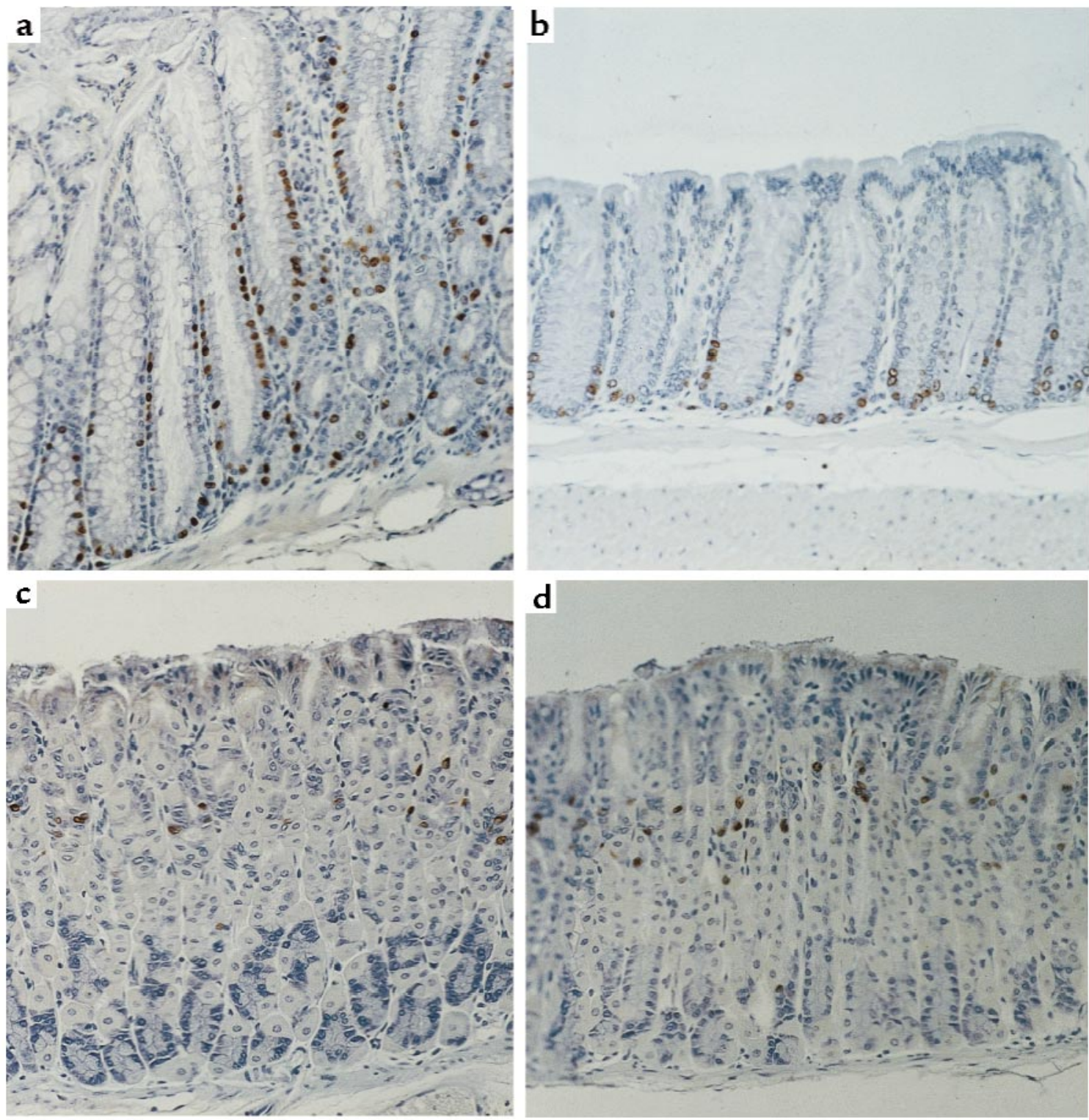

\section{Figure 4}

MTI/G-GLY mice have increased colonic proliferation with no change in gastric proliferation. Three-month-old mice were injected with BrdU (50 mg/kg intraperitoneally) one hour before sacrifice. There is increased BrdU labeling in the MTI/G-GLY mice (a), with a migration of the proliferative zone from the base of the crypts, when compared with age-controlled wild-type mice (b). There was no difference in the BrdU labeling index in the stomachs of MTI/GGLY mice (c) compared with wild-type mice (d). 


\section{Figure 5}

Infusion of G-Gly into gastrin-deficient mice results in increased colonic proliferation. (a) Infusion of G-Gly results in a significant increase in the BrdU labeling index in gastrindeficient mice when compared with infusion of saline or amidated G-17. (b) Mice receiving G-Gly have hypertrophied colonic crypts when compared with those receiving saline (c). a

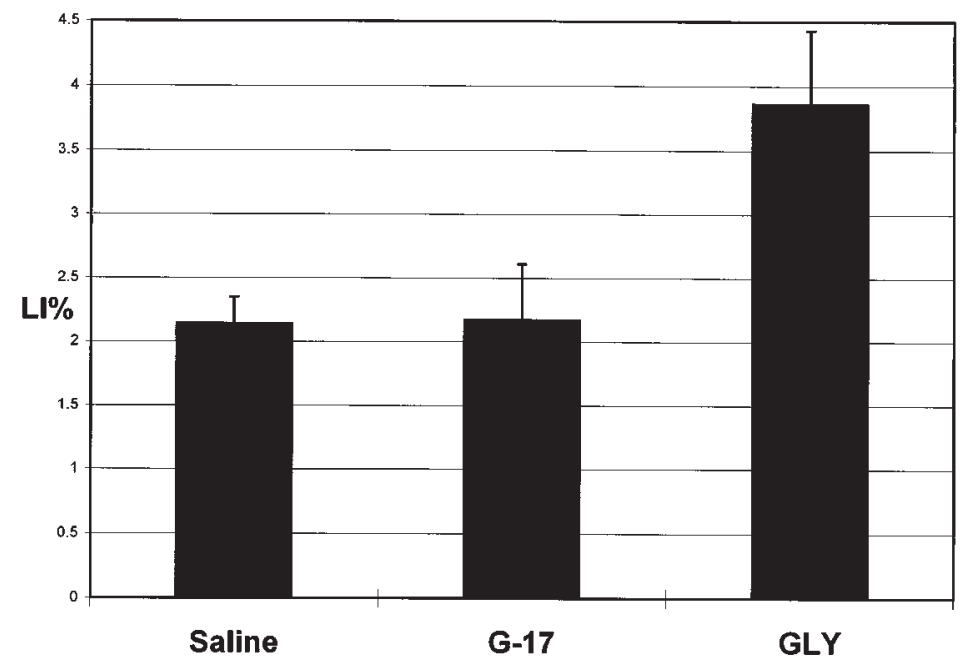

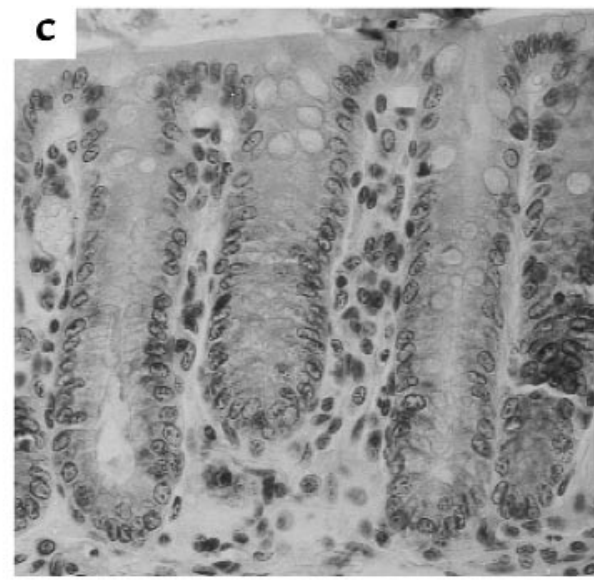

logic evaluation. One rectal sarcoma was found in the MTI/G-GLY mice. No gross or histologic abnormalities were seen in the stomach, liver, or pancreas.

Three of $10 \mathrm{MTI} / \mathrm{G}-\mathrm{GLY}$ mice were found to have lung bronchoalveolar carcinomas, whereas none of the control mice had evidence of lung tumors. It has been reported that human bronchogenic carcinomas express progastrin and, to a lesser extent, glycine-extended and amidated gastrin (13). However, it has also been reported that the FVB strain of mice used in generating the MTI/G-GLY transgenic mice develop bronchoalveolar carcinoma at an incidence of $20 \%$ at 14 months (35). There were insufficient numbers of mice in this study to determine whether overexpression of G-Gly increased the risk of developing bronchoalveolar carcinoma in FVB mice.

Table 1

Effect of MTI/G-GLY transgene on proliferation of the colon and the stomach

\begin{tabular}{lll} 
& MTI/G-GLY & Wild-type \\
& $3.17 \pm 0.29$ & $3.27 \pm 0.61$ \\
Stomach (LI\%) & $9.03 \pm 1.13^{\mathrm{A}}$ & $4.14 \pm 1.01$ \\
\hline
\end{tabular}

Three-month-old mice were injected with $\mathrm{BrdU}(50 \mathrm{mg} / \mathrm{kg}$ intraperitoneally) one hour before sacrifice. The BrdU labeling index was determined by counting the number of BrdU-stained cells compared with the number of cells per gland in the stomach and per crypt in the colon. ${ }^{A} P<0.05$ vs. wild-type.
Infusion of G-Gly into gastrin-deficient mice results in increased colonic proliferation with colonic mucosal bypertrophy. We have previously shown that gastrin-deficient mice have decreased basal colonic proliferation. To see whether G-Gly can correct the proliferation defect seen in gastrin-deficient mice, Alzet pumps were implanted into gastrin-deficient mice to deliver G-17-GLY, G-17, or saline as a constant infusion. Serum samples taken one week after initiation of G-Gly infusion revealed elevated serum levels of G-17-GLY (638 pM) with undetectable levels of G-17. Mice receiving amidated gastrin had similar levels of G-17 (685 pM) and undetectable levels of G17-GLY. Gastrin-deficient mice receiving saline had undetectable levels of either form of gastrin. The gastrindeficient mice that received G-Gly by continuous infusion over two weeks demonstrated increased colonic proliferation by BrdU staining (Figure 5a) compared with gastrin-deficient mice that received saline $(3.86 \pm 0.57 \mathrm{vs}$. $2.14 \pm 0.21 ; P<0.01)$. There was no difference seen in the BrdU labeling index in the colon of gastrin-deficient mice that received amidated gastrin $(2.17 \pm 0.44)$ compared with those receiving saline, despite the fact that there was a significant increase in fundic proliferation in the stomachs of mice receiving amidated gastrin (4.11 \pm $0.54)$ compared with those receiving saline $(2.79 \pm 0.41$; $P<0.05)$ or G-Gly $(2.89 \pm 0.46 ; P<0.05)$. Wild-type mice had a basal colonic proliferative rate of $3.75 \pm 0.05$. On 
routine histology (Figure 5, b and c), the colonic mucosa of the gastrin-deficient mice that received G-Gly was significantly thicker $(0.617 \pm 0.017 \mathrm{~mm})$ than those that received saline alone $(0.562 \pm 0.023 \mathrm{~mm} ; P<0.05)$.

\section{Discussion}

To our knowledge, this is the first study to express a glycine-extended form of gastrin in a mouse model. The MTI/G-GLY transgenic mice express the G-Gly transgene throughout the gastrointestinal tract, including the colon. This results in elevated concentrations of G-Gly in the serum and the colonic mucosa compared with those normally found in previous studies (20) (normal levels in rodents are $0.1-0.5 \mathrm{pmol} / \mathrm{g}$ and were below the limits of detection of our assays in this study).

Overexpression of G-Gly resulted in an increase in the proliferative index in the colon, with an expansion of the proliferative zone away from the base of the crypts. The proliferative effect was $218 \%$ greater than that seen in wild-type mice, resulting in an increase in the thickness of the colonic mucosa along with colonic goblet cell hyperplasia of MTI/G-GLY mice when compared with wild-type mice. Goblet cell hyperplasia has been reported in other rodent models in which colonic proliferation has been induced $(36,37)$.

There was a trend toward increased colonic proliferation seen in MTI/G-GLY when compared with mice that have markedly elevated serum levels of human progastrin $(20 \mathrm{nM})$ but normal levels in the colon $(9.03 \pm 1.13$ vs. $7.46 \pm 1.91 \mathrm{LI} \% ; P=0.10)$. This may reflect a receptor preference for G-Gly over progastrin. Alternatively, this may reflect the importance of local synthesis and release of G-Gly in the colonic mucosa through a paracrine or an autocrine effect.

The major form of G-Gly found in the serum of MTI/GGLY mice was G-34-GLY. G-34-GLY is the major processing intermediate of progastrin; G-34-GLY in turn is processed into either G-34 (which is the precursor for G17) or G-17-GLY (8). To our knowledge, this is the first study to demonstrate a biologic effect of G-34-GLY. All previous studies looking at the biologic activity of G-Gly have used either exogenous G-17-GLY or assayed for the presence of $\mathrm{COOH}$-terminal immunoreactivity. In our study, both overexpression of G-34-GLY in transgenic mice and infusion of G-17-GLY led to increased colonic proliferation. In addition, infusion of G-17, which has an identical $\mathrm{NH}_{2}$-terminus as G-17-GLY, had no effect on colonic proliferation in doses sufficient to stimulate fundic proliferation in the stomach. Taken together, these results suggest that it is the COOH-terminus of G-Gly that is important for the trophic effects seen in the colon. This would be similar to what is seen with the amidated gastrins G-34 and G-17, which also have equal biologic activity though their interaction with the CCK-B receptor (1).

The increased colonic proliferation seen in gastrin-deficient mice infused with G-17-GLY suggests that the actions of G-Gly can be mediated by an extracellular mechanism. Three candidate receptors (non-CCK-B) for G-Gly have been reported: a $78-\mathrm{kDa}$ protein identified from porcine gastric mucosal membranes (17), a 45-kDa protein identified from Swiss $3 \mathrm{~T} 3$ fibroblasts (16), and a protein identified from the pancreatic cell line AR4-2J (15). Because of the difficulty in synthesizing full-length progastrin, progastrin binding studies with the aforementioned candidate receptors have not been performed.

The MTI/G-GLY mice exhibited not only an increased rate of colonic proliferation but also an expansion of the proliferative zone into the upper third of the crypts. The presence of an increased rate of proliferation and a shift of the proliferative zone have both been shown to occur with increased frequency in patients at increased risk of developing colon cancer $(38,39)$. Subsequent studies have shown that these two findings correlate strongly with an increased risk of developing colon cancer (29, $30)$. Despite the increased proliferation seen in MTI/GGLY mice, there were no colonic tumors seen in the MTI/G-GLY mice over one year of follow-up. This suggests that glycine-extended progastrin overexpression is not sufficient to cause colon cancer in mice; a first "hit" is needed to initiate tumor formation. The MTI/G-GLY mice may provide a useful reagent in studying the effects of glycine-extended progastrin on previously established models of colon cancer, such as the Apc ${ }^{\text {min- }}$ mice and the methylazoxymethane-induced colon cancer model.

To our knowledge, this article provides the first in vivo evidence that G-Gly can exert a trophic effect on the mouse colon, resulting in a marked colonic mucosal hypertrophy with goblet cell hyperplasia. This was seen in both the MTI/G-GLY mice, which overexpress G-Gly in both the serum and in the colon, as well as in gastrin-deficient mice that were infused with G-Gly. This result supports the notion of a novel gastrin receptor that recognizes nonamidated forms of gastrin. The marked increase in the colonic mucosal proliferation rate with an expansion of the proliferative zone into the upper third of the colonic crypt also suggests that elevated levels of G-Gly may increase the risk for developing colorectal cancer.

\section{Acknowledgments}

This research was supported by National Institutes of Health (NIH) research grant R01 DK-52778 to T.C. Wang. A. Varro and G.J. Dockray were supported by grants from the Medical Research Council and Wellcome Trust. T.J. Koh was supported by a research grant from the NIH (K08 DK02545-01) and by the American Digestive Health Foundation/American Gastroenterological Association Advanced Research Training Award. Oligonucleotides were provided by the Center for Studies of Inflammatory Bowel Disease at Massachusetts General Hospital. Antibodies 109-21 and 1295 were kindly donated by John Walsh (CURE, University of California-Los Angeles, Los Angeles, California, USA).

\footnotetext{
1. Walsh, J.H. 1994. Gastrin. In Gut peptides. J.H. Walsh and G.J. Dockray, editors. Raven Press. New York, NY. 75-121.

2. Johnson, L.R. 1977. New aspects of the trophic action of gastrointestinal hormones. Gastroenterology. 72:788-792.

3. Willems, G., Vansteenkiste Y., and Limbosch, J.M. 1972. Stimulating effect of gastrin on cell proliferation kinetics in canine fundic mucosa. Gastroenterology. 62:583-589.

4. Crean, G.P., Marshall M.W., and Rumsey, R.D.E. 1969. Parietal cell hyperplasia induced by the administration of pentagastrin to rats. Gastroenterology. 57:147-155.

5. Wang, T.C., et al. 1996. Processing and proliferative effects of human progastrin in transgenic mice. J. Clin. Invest. 98:1918-1929.

6. Koh, T.J., et al. 1997. Gastrin deficiency results in altered gastric differentiation and decreased colonic proliferation in mice. Gastroenterology. 113:1015-1025.

7. Dockray, G.J., and Varro, A. 1993. Post-translational processing. In Gas-
} 
trin. J.H. Walsh, editor. Raven Press. New York, NY. 33-46.

8. Varro A., Voronina, A., and Dockray, G.J. 1995. Pathways of processing of the gastrin precursors in rat antral mucosa. J. Clin. Invest. 95:1642-1649.

9. Rehfeld, J.F., and van Solinge, W.W. 1994. Tumor biology of gastrin and cholecystokinin. Adv. Cancer Res. 63:295-347.

10. Kochman, M.L., DelValle, J., Dickinson, C.J., and Boland, C.R. 1992. Posttranslational processing of gastrin in neoplastic human colonic tissues. Biochem. Biophys. Res. Commun. 189:1165-1169.

11. Van Solinge, W.W., Nielsen, F.C., Friis-Hansen, L., Falkmer, U.G., and Rehfeld, J.F. 1993. Expression but incomplete maturation of progastrin in colorectal carcinoma. Gastroenterology. 104:1099-1107.

12. Nemeth, J., Taylor, B., Pauwels, S., Varro, A., and Dockray, G.J. 1993. Identification of progastrin derived peptides in colorectal carcinoma extracts. Gut. 34:90-95.

13. Rehfeld, J.F., Bardram, L., and Hilsted, L. 1989. Gastrin in human bronchogenic carcinomas: constant expression but variable processing of progastrin. Cancer Res. 49:2840-2843.

14. Van Solinge, W.W., Odum, L., and Rehfeld, J.F. 1993. Ovarian cancers express and process progastrin. Cancer Res. 53:1823-1828.

15. Seva, C., Dickinson, C.J., and Yamada, T. 1994. Growth promoting effects of glycine-extended progastrin. Science. 265:410-412.

16. Singh, P., Owlia, A., Espejo, R., and Dai, B. 1995. Novel gastrin receptor mediates mitogenic effects of gastrin and processing intermediates of gastrin in Swiss 3 T3 fibroblasts. J. Biol. Chem. 270:8429-8438.

17. Baldwin, G.S. 1995. Binding of progastrin fragments to the $78 \mathrm{kDa}$ binding protein. FEBS Lett. 359:97-100.

18. Hollande F., et al. 1997. Glycine-extended gastrin acts as an autocrine growth factor in a nontransformed colon cell line. Gastroenterology. 113:1576-1588.

19. Todisco, A., Takeuchi, Y., Seva, C., Dickinson, C.J., and Yamada, T. 1995. Gastrin and glycine-extended progastrin processing intermediates induce different programs of early gene activation. J. Biol. Chem. 270:28337-28341.

20. Luttichau, H.R., van Solinge, W.W., Nielsen, F.C., and Rehfeld, J.F. 1993. Developmental expression of the gastrin and cholecystokinin genes in rat colon. Gastroenterology. 104:1092-1098.

21. Monstein, H.J., et al. 1996. Cholecystokinin-A and cholecystokinin$\mathrm{B} /$ gastrin receptor mRNA expression in the gastrointestinal tract and pancreas of the rat and man. Scand. J. Gastroenterol. 31:383-390.

22. Ciccotosto, G.D., McLeish, A., Hardy, K.J., and Shulkes, A. 1995. Expression, processing, and secretion of gastrin in patients with colorectal carcinoma. Gastroenterology. 109:1142-1153.

23. Singh, P., et al. 1996. Gastrin gene expression is required for the proliferation and tumorigenicity of human colon cancer cells. Cancer Res. 56:4111-4115.

24. Baldwin, G.S. 1994. Anti-proliferative gastrin/cholecystokinin antago- nists target the $78 \mathrm{kDa}$ gastrin-binding protein. Proc. Natl. Acad. Sci. USA. 91:7593-7597.

25. Hoosien, N.M, et al. 1988. Antiproliferative effects of gastrin receptor antagonists and antibodies on human colon carcinoma cell lines. Cancer Res. 48:7179-7183.

26. Beauchamp, R.D., Townsend, C.M., Singh, P., Glass, E.J., and Thompson, J.C. 1985. Proglumide, a gastrin receptor antagonist, inhibits growth of colon cancer and enhances survival of mice. Ann. Surg. 202:303-309.

27. Sobhani, I.J., et al. 1993. Chronic endogenous hypergastrinemia in humans: evidence for a mitogenic effect on the colonic mucosa. Gastroenterology. 105:22-30.

28. Renga, M., et al. 1997. Rectal cell proliferation and colon cancer risk in patients with hypergastrinemia. Gut. 41:330-332.

29. Bostick, R.M., et al. 1997. Colorectal epithelial cell proliferative kinetics and risk factors for colon cancer in sporadic adenoma patients. Cancer Epidemiol. Biomarkers Prev. 6:1011-1019.

30. Eastwood, G.L. 1995. A review of gastrointestinal epithelial renewal and its relevance to the development of adenocarcinomas of the gastrointestinal tract. J. Clin. Gastroenterol. 21(Suppl. 1):S1-S11.

31. Low, M.J., et al. 1985. Tissue-specific posttranslational processing of presomatostatin encoded by a metallothionein-somatostatin fusion gene in transgenic mice. Cell. 41:211-219.

32. Wang, T.C., et al. 1993. Pancreatic gastrin stimulates islet differentiation of transforming growth factor $\alpha$-induced ductular precursor cells. J. Clin. Invest. 92:1349-1356.

33. Dockray, G.J. 1980. Immunochemical studies on big gastrin using $\mathrm{NH}_{2}$ terminal specific antisera. Regul. Pept. 1:169-186.

34. Dockray, G.J., and Walsh, J.H. 1975. Amino terminal gastrin fragment in serum of Zollinger-Ellison syndrome patients. Gastroenterology. 68:222-230.

35. Mahler, J.F., Stokes, W., Mann, P.C., Takaoka, M., and Maronpot, R.R. 1996. Spontaneous lesions in aging FVB/N mice. Toxicol. Pathol. 24:710-716

36. Olubuyide, I.O., Williamson, R.C.N., Bristol, J.B., and Read, A.E. 1984. Goblet cell hyperplasia is a feature of the adaptive response to jejunoileal bypass in rats. Gut. 25:62-68.

37. Olubuyide, I.O., Bristol, J.B., and Williamson, R.C.N. 1985. Goblet cell changes during intestinal adaptation to azoxymethane and enteric bypass in the rat. Br. J. Cancer. 51:383-388.

38. Terpstra, O.T., vanBlankenstein, M., Dees, J., and Eilers, G.A. 1987. Abnormal pattern of cell proliferation in the entire colonic mucosa of patients with colon adenoma or cancer. Gastroenterology. 92:704-708.

39. Lipken, M., et al. 1984. Classification and risk assessment of individuals with familial polyposis, Gardner's syndrome, and familial non-polyposis colon cancer from $\left[{ }^{3} \mathrm{H}\right]$ thymidine labeling patterns in colonic epithelial cells. Cancer Res. 44:4201-4207. 